\title{
A HOPPER FOR USE WHEN SIEVING BOTTOM SAMPLES AT SEA
}

\author{
By N. A. Holme \\ The Plymouth Laboratory
}

(Text-figs. I and 2)

When large quantities of bottom soil are brought up by the dredge or grab, the problem of sieving the material within a reasonable time presents itself. The usual practice is to wash the soil through a sieve or series of sieves, the finest being of the order of I-2 mm aperture, according to the nature of the soil or the size of the animals to be collected. It is usually necessary to agitate the soil either by spraying with a hose or by shaking the sieve in a bath of water, in order that finer particles may pass through the sieve. Many of the more delicate animals are damaged by these methods, and Spooner \& Moore (1940), working on the Tamar estuary, found it necessary to mix the mud carefully by hand with water to make a 'soup' before it could be sieved without damage to the fauna. For work at sea Hartman (1955) describes a machine by which sieving was accomplished with the aid of water sprays and mechanical agitation of the sieves with power provided by an electric motor.

The apparatus to be described provides a semi-automatic means of washing soil into suspension in sea water, the resulting suspension passing fairly readily through a sieve. The animals are little damaged by this method, as once the soil has been placed in the hopper it remains undisturbed until washed over into the sieve. The method is probably no faster than others, but the physical labour of sieving is almost eliminated and the apparatus can be left to run unattended while further samples are being taken. The apparatus may be used on any ship having an adequate water supply to the deck.

It consists essentially of a square wooden hopper, some $18 \mathrm{in}$. $(46 \mathrm{~cm})$ across, into which the whole sample of soil is tipped, standing on a sloping V-shaped wooden base. The base is supported on four legs, to such a height that a sieve can be placed beneath the spout at its lower end. The two halves of the base are each inclined at about $23^{\circ}$ to the horizontal, while along its axis the base slopes down towards the spout at an angle of $10^{\circ}$. The base has low walls at its sides which stop the water spilling out as the ship rolls. There is a gap of $4 \mathrm{~cm}$ between the base and three sides of the hopper, around which water from the overhead jets flows, slowly, eroding the outside of the pile. At the lower side of the hopper is a rising 'gate' which is lowered as necessary to retain the sample when the hopper is being filled. 


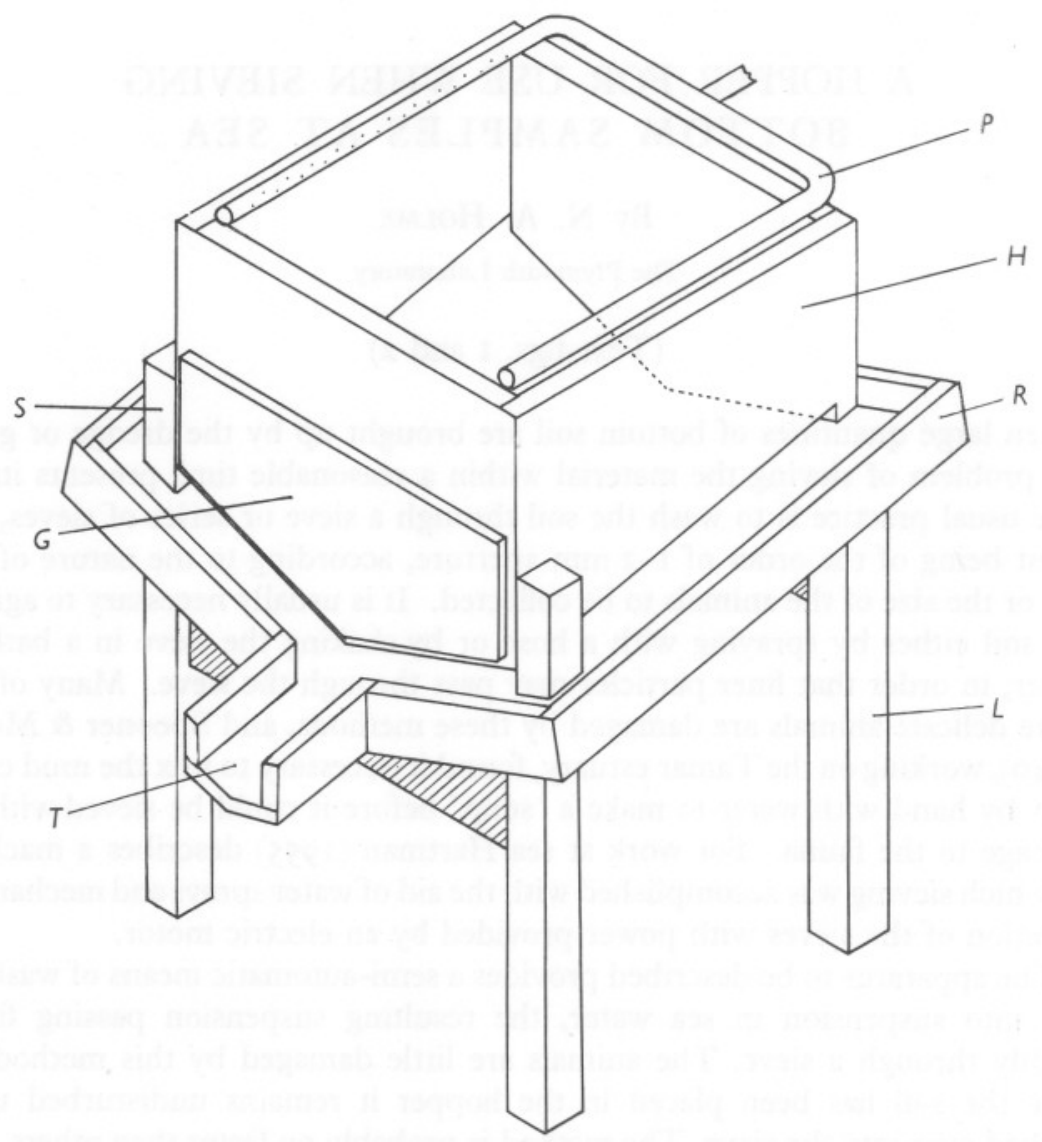

Fig. I. General view of the hopper (isometric projection). Some constructional details are omitted. $P$, pipe supplying the jets along the top of the hopper; $H$, side wall of the hopper; $R$, retaining wall at side of base; $T$, spout; $G$, rising gate; $S$, short legs supporting lower side of hopper clear of base; $L$, legs supporting base.

The soil is broken down by jets of water issuing from rows of small holes in two lengths of pipe running along the top of two sides of the hopper. One inch bore polythene pipe, sealed at the outer end, has been used, and by using Yorkshire 'plastronga' elbow joints it is possible to vary the angle of the jets as required. The jets are arranged to fall at different angles to cover the surface of the soil in the hopper as completely as possible. Water accumulating on the surface excavates for itself cavities at the side of the heap, so draining down to the bottom of the hopper. Thence it travels around the base of the pile, out through the spout and into the sieve. It has not been found necessary to make an overflow near the top of the hopper, as the water always drains 



Fig. 2. A, Transverse section of the hopper just above the spout. $B$, base; $O$, soil in hopper, showing eroding outer edge of the pile. Other lettering as in Fig. I. B, Top view of the hopper. 
away satisfactorily. Small animals and all fine material are washed over into the sieve; large animals and stones remain in the hopper, from which they may have to be removed from time to time if they cause obstruction to the flow of water.

Although the hopper may be left to run on its own for short periods, washing is speeded if the surface of the soil is occasionally stirred with a trowel. Lumps of mud are nearly always broken up before reaching the sieve, but where there is much shell or gravel the sieve becomes blocked from time to time. If this happens the sieve is thoroughly washed in a bath of water and the contents emptied out before continuing any further sieving.

Washing is little affected by the ship's motion, and the hopper can be used in any weather in which dredging or grab sampling is likely to be undertaken.

The use of a nest of sieves of decreasing mesh size is unsatisfactory with this hopper, since one or other of the sieves will soon choke and overflow if left unattended. The sieves used have a rectangular wood frame $45 \times 35 \times 20$ $\mathrm{cm}$ deep (a sieve of larger area would no doubt be less often clogged, but this size was chosen as convenient for rinsing the sieve in a bath of water). The sieve has a handle at each end, and short legs at the corners to raise the gauze screen clear of the deck. A sieve in which the gauze is curved into an arc of a circle is less easily blocked than a flat one, and the sieves are provided with a side-window of gauze to prevent overflowing (cf. Spooner \& Moore, I940). A square or rectangular sieve is easier to empty than a round one, as the sievings can be washed into a corner and then rinsed into a jar with a little water.

I am indebted to Mr A. N. Bennett and to Mr F. G. C. Ryder and his workshop staff for constructing this apparatus, and to Mr P. G. Corbin for his helpful criticism of the manuscript.

\section{SUMMARY}

A hopper is described which facilitates the sieving of large quantities of bottom soil at sea. It can be left unattended for short periods, and considerably reduces the labour involved in sieving. Animals are probably less damaged by this than by the usual methods, as there is considerably less disturbance in the sieve. The apparatus may be used on any ship where there is an adequate water supply to the deck, and it can be operated successfully in moderately rough weather.

\section{REFERENCES}

Hartman, O., I955. Quantitative survey of the benthos of San Pedro Basin, Southern California. Part I. Preliminary results. Allan Hancock Pacific Expeditions, Vol. I9, No. I, I85 pp.

SPOONER, G. M. \& MOoRE, H. B., I940. The ecology of the Tamar estuary. VI. An account of the macrofauna of the intertidal muds. F. mar. biol. Ass., U.K., Vol. 24, pp. 283-330. 